\title{
Effect of tiotropium on sputum and serum inflammatory markers and exacerbations in COPD
}

\author{
D.J. Powrie*,+, T.M.A. Wilkinson ${ }^{\#,+}$, G.C. Donaldson ${ }^{\#,+}$, P. Jones ${ }^{*}$, \\ K. Scrine", K. Viel", S. Kesten ${ }^{\natural}$ and J.A. Wedzicha ${ }^{\#,+}$
}

ABSTRACT: Chronic obstructive pulmonary disease (COPD) patients experiencing frequent exacerbations demonstrate increased stable-state airway inflammation. Tiotropium has been shown to reduce exacerbation frequency, but its effect on airway inflammation is unknown. The aim of the present study was to investigate the effect of tiotropium on sputum inflammatory markers and exacerbation frequency.

Patients $(n=142)$ were randomised to receive tiotropium or placebo in addition to their usual medication for 1 yr. Sputum and serum cytokines were assayed by ELISA and exacerbation frequency calculated using a symptom-based diary.

There was no difference in the area under the curve for sputum interleukin (IL)- 6 or myeloperoxidase between the groups, but sputum IL-8 level was increased in the tiotropium arm. There was no difference between start and end of study in serum IL- 6 or C-reactive protein level. Tiotropium was associated with a $52 \%$ reduction in exacerbation frequency ( 1.17 versus 2.46 exacerbations $\left.\cdot \mathrm{yr}^{-1}\right)$. Of patients on tiotropium, $43 \%$ experienced at least one exacerbation, compared with $64 \%$ on placebo. The total number of exacerbation days was reduced compared with placebo (17.3 versus 34.5 days).

Tiotropium reduces exacerbation frequency in chronic obstructive pulmonary disease, but this effect does not appear to be due to a reduction in airway or systemic inflammation.

KEYWORDS: Anticholinergic, cytokines, sputum

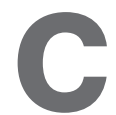
hronic obstructive pulmonary disease (COPD) is an inflammatory disease of the airways, resulting in a progressive irreversible decline in respiratory function. Patients with COPD experience acute exacerbations characterised by worsening symptoms, deterioration in lung function and increased airway inflammation [1, 2]. Exacerbations are a major cause of morbidity and mortality, and have major resource implications for the treatment of COPD $[3,4]$.

Patients suffering more frequent exacerbations report worse quality of life, are more likely to become housebound and exhibit increased mortality $[3,5,6]$. Frequent exacerbations are associated with a faster decline in lung function, and it has been shown that patients experiencing more frequent exacerbations demonstrate increased airway inflammation in the stable state
$[7,8]$. Therefore, reducing exacerbation frequency is clearly an important objective in the management of COPD.

Tiotropium is a once-daily inhaled anticholinergic bronchodilator. Long-term studies have demonstrated improvements in forced expiratory volume in one second (FEV1), forced vital capacity (FVC), lung volumes, health-related quality of life and exercise capacity [9-13]. In addition, previous studies have reported reductions in exacerbation frequency [9-11]. Recent prospective multicentre studies have shown an increase in time to first exacerbation with tiotropium compared with placebo, as well as a reduction in exacerbation frequency, hospitalisations and healthcare utilisation $[14,15]$; however, the mechanism of this reduction in exacerbations is unknown.

It has been shown that acetylcholine increases neutrophil chemotactic activity in COPD, and

\section{AFFILIATIONS}

*Southend University Hospital, Westcliff-on-Sea,

\#Academic Unit of Respiratory

Medicine, Royal Free and University College Medical School, London, and

"Boehringer-Ingelheim, Bracknell, UK.

${ }^{+}$The present study was carried out while D.J. Powrie, T.M.A. Wilkinson, G.C. Donaldson and J.A. Wedzicha were affiliated to the Dept of Academic Respiratory Medicine, St Bartholomew's Hospital, London, UK.

\section{CORRESPONDENCE}

J.A. Wedzicha

Academic Unit of Respiratory

Medicine

Royal Free and University College

Medical School

Rowland Hill Street

London

NW3 2PF

UK

Fax: 44207472614

E-mail: j.a.wedzicha@

medsch.ucl.ac.uk

Received:

February 282007

Accepted after revision:

April 232007

\section{STATEMENT OF INTEREST}

Statements of interest for D.J. Powrie,

T.M.A. Wilkinson, P. Jones, K.

Scrine, K. Viel, S. Kesten and J.A.

Wedzicha, and for the study itself,

can be found at

www.erj.ers.journals.com/misc/

statements.shtml 
that this effect is attenuated in vitro by tiotropium, thus providing a possible anti-inflammatory mechanism of action $[16,17]$. There is a close relationship between airway inflammation and exacerbation frequency, and it might be postulated that a reduction in stable-state airway inflammation would result in a reduction in exacerbation frequency.

There have been several short-term studies on the effect of COPD therapies on airway inflammation [18-21]. The present authors hypothesised that tiotropium might reduce airway inflammation and that this would lead to a reduction in exacerbation frequency. Thus the aim of the present trial was to study, for the first time, the effect of inhaled tiotropium on airway and systemic inflammatory markers in COPD in a 1-yr randomised placebo-controlled study. The effect of tiotropium on exacerbation frequency was also studied, using symptombased diary cards. Results from the present study have previously been presented in the form of abstracts [22, 23].

\section{METHODS}

Study design

The present study was a 1-yr, single-centre, double-blind, randomised, placebo-controlled trial to assess the effect of tiotropium on sputum inflammatory markers and exacerbation frequency. Ethics approval was obtained from the East London and the City Research Ethics Committee (London, UK), the study was registered on ClinicalTrials.gov (NCT00405236) [24] and all patients gave written informed consent. The primary end-point was the concentration of interleukin (IL)-6 in sputum. Secondary end-points included sputum IL-8 and myeloperoxidase (MPO) levels, serum IL-6 and C-reactive protein (CRP) levels, sputum bacterial colonisation, FEV1 and exacerbation frequency.

\section{Patient selection}

Patients aged $\geqslant 40$ yrs with a diagnosis of COPD (FEV $1<80 \%$ of the predicted value and FEV1/FVC $<70 \%$ ) and a minimum 10-pack-yr smoking history were recruited from primary care or the outpatients department of the London Chest Hospital (London, UK). Patients with a history of asthma or atopy were excluded, as were those on long-term oxygen therapy or with another clinically significant disease. Anticholinergics other than the study drug were not permitted during the course of the study.

\section{Study protocol}

Subjects were randomised to $18 \mu \mathrm{g}$ tiotropium q.d. or placebo via the HandiHaler device (Boehringer-Ingelheim, Bracknell, UK). They were provided with diary cards for recording daily symptoms, morning peak flow and drug compliance, and baseline sputum and blood samples were collected.

Patients were seen at weeks 4, 16, 32 and 52 after randomisation. Spirometry was performed, a sputum sample obtained and diaries were examined. Additionally, at weeks 32 and 52, serum samples were collected and patients asked about any change in sputum production.

\section{Laboratory analyses}

Patients provided spontaneous or induced sputum samples as previously described [25]. Following processing, sputum IL-6, IL- 8 and MPO and serum IL-6 and CRP were quantified by
ELISA. A portion of the sputum sample underwent quantitative and qualitative bacteriological analysis [26, 27]. Further details of these analyses are provided in the online data supplement.

\section{Exacerbations}

Patients were asked to record any increase in their respiratory symptoms above their normal stable condition using a letterannotated system in their diary. The diagnosis of an exacerbation was based upon symptomatic criteria previously validated by the East London COPD Study Group (London, $\mathrm{UK})[1,5,7]$. An exacerbation was defined as the presence, for $\geqslant 2$ days consecutively, of an increase in any two major symptoms (dyspnoea, sputum purulence and sputum volume) or in one major and one minor symptom (wheeze, sore throat, cough and symptoms of a common cold).

\section{Statistics}

Analyses were carried out using the full analysis dataset (all randomised treated patients with efficacy data), using ANCOVA that adjusted for smoking status and exacerbation history over the previous year $(<3$ or $\geqslant 3$ exacerbations), recorded on recruitment. For sputum markers, the area under the curve (AUC) was calculated for each patient, with missing data replaced by interpolation or the last observation carried forward. The model also included baseline inflammatory marker levels as a covariate. AUCs for IL-6 and MPO were skewed and therefore log10-transformed. For lung function, comparisons were made between changes from the start to the end of the study. The pre-specified data analysis with AUCs was chosen for its ability to estimate the total effect of tiotropium on sputum and serum cytokines over 1 yr rather than the effect at a single time-point [28]. Additional analysis was also carried out using cross-sectional regression models. Systemic inflammatory markers were not sampled at weeks 4 and 16; thus comparisons were made by Wilcoxon signed-rank test between changes from baseline to the final sample.

The effect of tiotropium on individual annual rates (number of exacerbations multiplied by $365 /$ days on drug) was tested using a Wilcoxon test. Differences in time to the next exacerbation were examined using a log-rank test.

Exacerbation recovery times were calculated as the time for a 3-day moving average of peak flow to return, post-exacerbation, to a baseline taken as the average on days $14-8$ prior to exacerbation onset.

\section{RESULTS}

Figure 1 shows the trial profile of the 237 COPD patients who were enrolled into the study, 142 of whom were randomised (69 to tiotropium and 73 to placebo). The two treatment groups were well matched (table 1); 99 patients had a history of $<3$ exacerbations $\cdot \mathrm{yr}^{-1}$ (41 nonsmokers and 58 current smokers) and 43 patients $>3$ exacerbations $\cdot \mathrm{yr}^{-1}$ (18 nonsmokers and 25 current smokers; $\mathrm{p}=0.960$ using Chi-squared test).

\section{Sputum and serum inflammatory markers}

As a proportion of the patients remaining active in the study, $91,57,70,78$ and $67 \%$ of patients on tiotropium, and 90, 60, 66, 62 and $63 \%$ on placebo, produced a sputum sample at baseline, 1, 3, 6 and 12 months, respectively. Figure 2 shows the results 


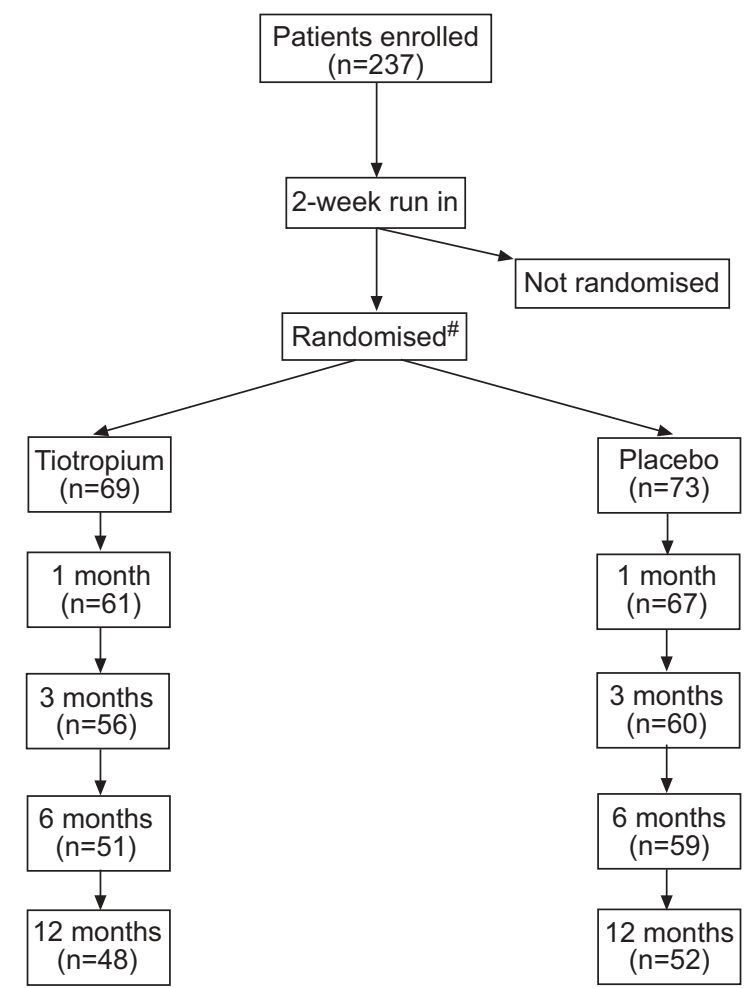

FIGURE 1. Profile of patients remaining in the study. ${ }^{*}$ : all randomised patients received at least one dose of the study treatment.

of the AUC analysis of sputum inflammatory markers. Table 2 shows that there was no difference in the log10-transformed AUC sputum IL-6 level in patients on tiotropium from that in those on placebo after adjustment for baseline values, exacerbation frequency and smoking status $(p=0.324)$. The AUC for sputum IL-8 level was $15.4 \%$ higher $(p=0.043)$ in patients on tiotropium than in those on placebo. In the analysis of sputum IL-8 level, smokers showed significantly higher AUCs $(\mathrm{p}=0.029)$. There were no significant differences in sputum MPO levels in patients on tiotropium compared with placebo $(\mathrm{p}=0.079)$. Inclusion in the analysis of whether the patients were taking inhaled steroids did not alter the findings. There was still no effect of tiotropium on sputum IL-6 level $(p=0.327)$ or sputum MPO level $(p=0.082)$. The AUC for sputum IL-8 level remained higher in patients on tiotropium $(p=0.047)$.

There was no significant difference between the groups in change in levels of serum IL-6 ( $p=0.691$ using Wilcoxon test) or CRP $(p=0.700)$ from baseline to week 52 (table 2). Further analysis using cross-sectional regression models, with similar allowance for exacerbation frequency, smoking habits and baseline levels, gave similar results. Tiotropium did not increase $\log 10$ sputum IL-6 concentration $(p=0.540)$. The effect of tiotropium on sputum IL-8 level was not significant $(p=0.055)$, whereas it caused $\log 10 \mathrm{MPO}$ level to rise by $0.156 \log 10 \mathrm{IU} \cdot \mathrm{L}^{-1}$ $(p=0.006)$. No significant differences were seen in log10 CRP $(p=0.456)$ or $\log 10$ serum IL-6 concentration $(p=0.058)$.

\section{Lung function}

During the trial, the mean \pm SD FEV1 of patients taking tiotropium rose from $1.35 \pm 0.47$ at baseline to $1.39 \pm 0.55 \mathrm{~L}$ at

\begin{tabular}{|c|c|c|c|c|}
\hline \multirow[t]{2}{*}{ TABLE 1} & \multicolumn{4}{|c|}{$\begin{array}{l}\text { Patient physical, smoking and exacerbation } \\
\text { characteristics and pre-study medication }\end{array}$} \\
\hline & & Tiotropium & Placebo & p-value \\
\hline \multicolumn{2}{|l|}{ Subjects n } & 69 & 73 & \\
\hline \multicolumn{2}{|l|}{ Males } & 69.6 & 56.2 & 0.099 \\
\hline \multicolumn{2}{|c|}{$\geqslant 3$ exacerbations last year } & 30.4 & 30.1 & 0.969 \\
\hline \multicolumn{2}{|c|}{ Current smoker } & 59.4 & 57.5 & 0.820 \\
\hline \multicolumn{2}{|c|}{ Age yrs } & $66.3 \pm 8.1$ & $66.4 \pm 9.8$ & 0.947 \\
\hline \multicolumn{2}{|c|}{ Body mass index $\mathrm{kg} \cdot \mathrm{m}^{-2}$} & $27.1 \pm 6.71$ & $27.1 \pm 6.15$ & 0.993 \\
\hline \multicolumn{2}{|c|}{ Smoking history pack-yrs } & $54.6 \pm 25.5$ & $55.7 \pm 28.0$ & 0.807 \\
\hline \multicolumn{2}{|c|}{ FEV $_{1} \mathrm{~L}$} & $1.35 \pm 0.47$ & $1.23 \pm 0.51$ & 0.148 \\
\hline \multicolumn{2}{|l|}{ FEV $1 \%$ pred } & $50.9 \pm 14.8$ & $49.2 \pm 15.6$ & 0.507 \\
\hline \multicolumn{2}{|l|}{ FVC L } & $2.29 \pm 0.75$ & $2.16 \pm 0.79$ & 0.317 \\
\hline \multicolumn{2}{|c|}{ PEFR weekly mean L·min ${ }^{-1}$} & $261.6 \pm 82.5$ & $236.4 \pm 84.5$ & 0.075 \\
\hline \multicolumn{5}{|c|}{ Pulmonary medication at baseline } \\
\hline \multicolumn{2}{|c|}{ Daily inhaled steroids } & 73.9 & 76.7 & 0.699 \\
\hline \multicolumn{2}{|c|}{ Daily oral steroids } & 4.3 & 1.4 & 0.284 \\
\hline \multicolumn{2}{|c|}{ Short-acting anticholinergics } & 44.9 & 45.2 & 0.973 \\
\hline \multicolumn{2}{|c|}{ Short-acting $\beta$-adrenergics } & 94.2 & 93.2 & 0.797 \\
\hline \multicolumn{2}{|c|}{ Long-acting $\beta$-adrenergics } & 42.0 & 43.8 & 0.828 \\
\hline \multicolumn{5}{|c|}{$\begin{array}{l}\text { Data are presented as per cent or mean } \pm \text { SD, unless otherwise stated. FEV1: } \\
\text { forced expiratory volume in one second; \% pred: \% predicted; FVC: forced vital } \\
\text { capacity; PEFR: peak expiratory flow rate. }\end{array}$} \\
\hline
\end{tabular}

$1 \mathrm{yr}$, whereas patients taking placebo experienced a fall from $1.26 \pm 0.49$ at baseline to $1.20 \pm 0.49 \mathrm{~L}$ at $1 \mathrm{yr}(\mathrm{p}=0.027)$.

The FVC of patients on tiotropium was unchanged between baseline and the end of treatment, at $2.26 \pm 0.79 \mathrm{~L}$, whereas patients in the placebo group experienced a decrease in FVC of $0.20 \mathrm{~L}$, from $2.21 \pm 0.81$ at baseline to $2.01 \pm 0.81 \mathrm{~L}$ at the end of treatment $(\mathrm{p}=0.003)$.

\section{Exacerbations}

The patients in the tiotropium-treated group experienced 60 exacerbations compared with 134 in the placebo arm (table 3). Patients on tiotropium showed fewer exacerbations per year (mean \pm SD 1.17 \pm 2.25 ; median (interquartile range) $0(0-1.0)$ ) compared with those on placebo $(2.46 \pm 3.82 ; 1.6$ (0-3.0); $\mathrm{p}=0.001$ using Wilcoxon test), representing a 52\% reduction in exacerbation frequency on tiotropium. The number of exacerbations in those treated with antibiotics or steroids was also reduced $(0.98 \pm 2.11$ in the tiotropium arm compared with $1.73 \pm 2.46$ on placebo; $p=0.007)$. Of the patients on tiotropium, $43 \%$ experienced at least one exacerbation during the study period, compared with $64 \%$ of those on placebo $(p=0.01$; fig. 3). Survival-time analysis indicated the mean time to first exacerbation was $236 \pm 143$ days (SEM 17.2) with tiotropium, compared with $157 \pm 124$ days (SEM 14.6) with placebo $(p=0.0092$ using log-rank test). There were significantly fewer exacerbation days in patients on tiotropium than in those receiving placebo $(17.3 \pm 33.6$ (median 0$)$ versus $34.5 \pm 47.5$ (median 21.7) days $\cdot \mathrm{yr}^{-1} ; \mathrm{p}=0.002$ using Wilcoxon test). This was due to a reduction in the number of exacerbations, as there was no difference in the length of the exacerbations, as 

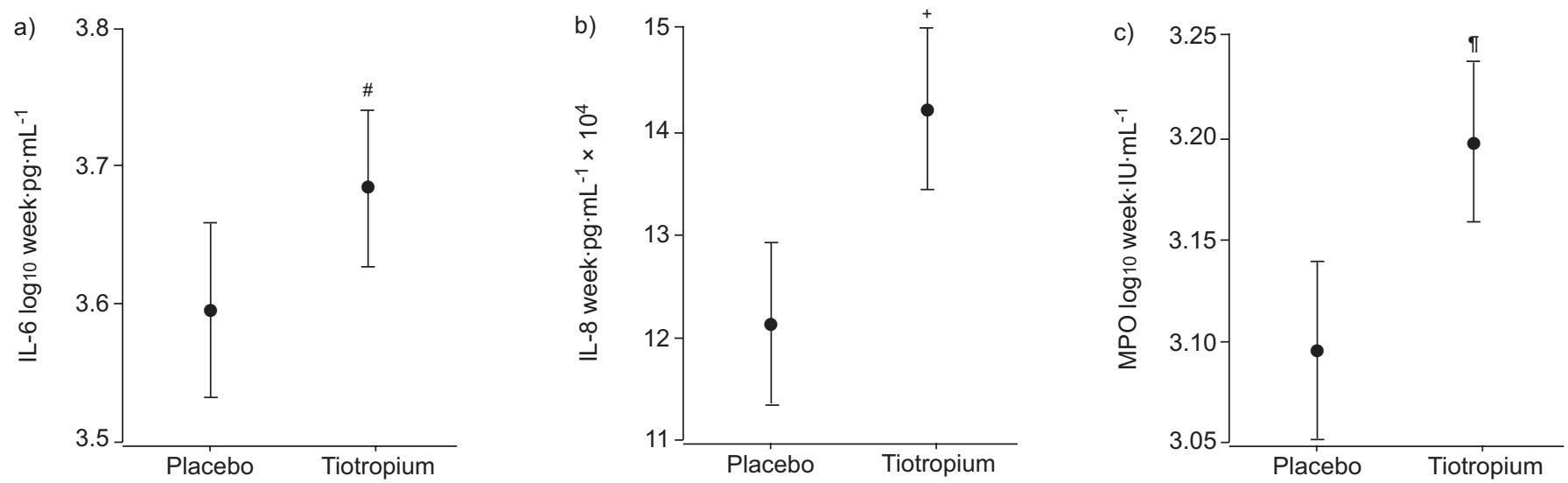

FIGURE 2. Areas under the curve (AUCs) of sputum inflammatory markers: a) interleukin (IL)-6; b) IL-8; and c) myeloperoxidase (MPO). AUCs for IL-6 and MPO were $\log 10$-transformed. Data are presented as mean \pm SEM. ${ }^{*}: p=0.324 ;{ }^{\bullet}: p=0.079 ;{ }^{+}: p=0.043$ versus placebo (ANCOVA with adjustment for exacerbation frequency and smoking).

indicated by symptom count recovery times: $9.89 \pm 6.94$ days on tiotropium versus $9.54 \pm 6.96$ days on placebo $(p=0.748)$.

There were no differences in the symptoms recorded at exacerbation onset in the 60 exacerbations of the tiotropium group and 134 exacerbations of the placebo group. Tiotropium was associated with a subjective reduction in sputum production in $33 \%$ of patients compared with $7.9 \%$ in the placebo group ( $\mathrm{p}=0.001$ using Chi-squared test).

There was no difference in the proportion of treated exacerbations in the tiotropium group, 50 (83.3\%) out of 60 , compared with $108(80.6 \%)$ out of 134 in the placebo group $(p=0.650$ using Chi-squared test). Two patients who experienced exacerbations on tiotropium were hospitalised, compared with three on placebo $(\mathrm{p}=0.657)$.

\section{Bacteria}

There were no differences in the proportion of any bacterial species identified at any time-point between tiotropium and placebo. The commonest species isolated was Haemophilus influenzae, present in $10-20 \%$ of patients at each time-point. Mean bacterial counts were similar at all time-points (at baseline: $1 \times 10^{6.6}$ colony-forming units $(\mathrm{cfu}) \cdot \mathrm{mL}^{-1}$ and $1 \times 10^{6.9} \mathrm{cfu} \cdot \mathrm{mL}^{-1}$ for patients on tiotropium and placebo, respectively; week 52 : $1 \times 10^{7.2}$ and $1 \times 10^{6.9} \mathrm{cfu} \cdot \mathrm{mL}^{-1}$, respectively).

\section{Study compliance and withdrawals}

Of patients receiving tiotropium, $82.6 \%$ took $>90 \%$ of their medication, compared with $90.4 \%$ of those on placebo $(p=0.172)$. Compliance with diary cards was also high. Patients on tiotropium recorded diary data for $94.5 \%$ of the time, whereas those on placebo recorded diary card data for $94.1 \%$ of the time.

Figure 1 shows that during the study, 21 (30.4\%) out of 69 patients on tiotropium withdrew before $1 \mathrm{yr}$, compared with $21(28.8 \%)$ out of 73 on placebo $(p=0.828)$. There were no significant differences in withdrawals at any other time-points. Seven $(10.1 \%)$ patients on tiotropium and $14(19.2 \%)$ on placebo withdrew due to an adverse event $(p=0.130)$.

\section{Adverse events}

Table 4 shows adverse events during treatment, excluding exacerbations. Most adverse events were mild or moderate in intensity. None of the adverse events were considered to be therapy related, with the exception of one episode of pruritus in the tiotropium group and one of palpitations in the placebo group.

TABLE 2 Areas under the curve of sputum inflammatory markers for tiotropium and placebo treatment arms

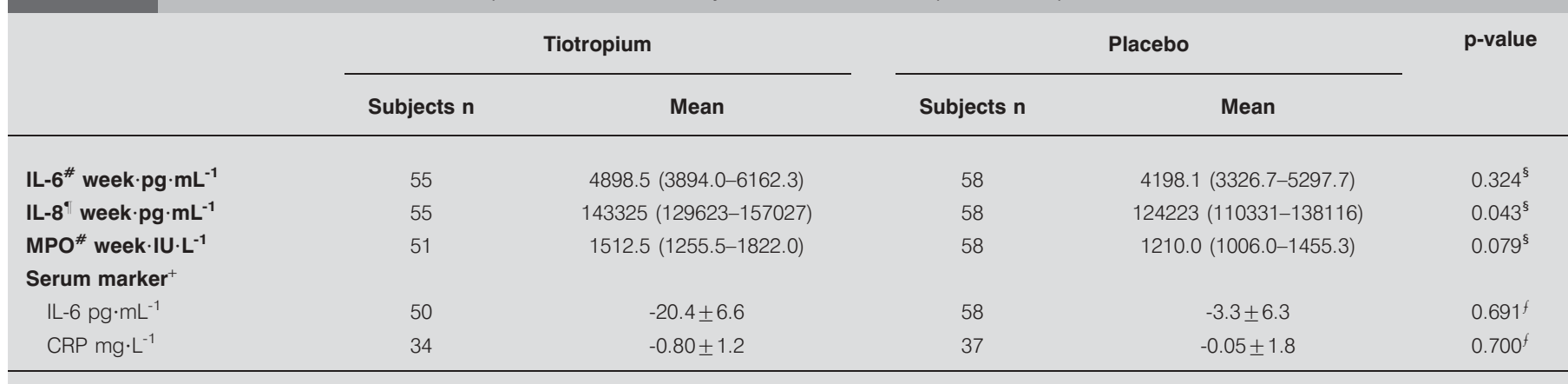

Data are presented as mean \pm SEM, unless otherwise stated. IL: interleukin; MPO: myeloperoxidase; CRP: C-reactive protein. ${ }^{\#}$ : means presented as geometric mean (95\% confidence interval), adjusted for baseline, exacerbation frequency and smoking status; ${ }^{\bullet}$ : means presented as mean (95\% confidence interval), adjusted for baseline, exacerbation frequency and smoking status; ${ }^{+}$: change from baseline to week $52 ;{ }^{\S}$ : ANCOVA; ${ }^{f}$ : Wilcoxon signed-rank test. 


\begin{tabular}{|c|c|c|c|}
\hline Rate exacerbations $\cdot \mathrm{yr}^{-1}$ & $1.17 \pm 2.25$ & $2.46 \pm 3.82$ & 0.001 \\
\hline Rate treated exacerbations $\cdot \mathrm{yr}^{-1}$ & $0.98 \pm 2.11$ & $1.73 \pm 2.46$ & 0.007 \\
\hline Patients with no exacerbations during study \% & 56.5 & 35.6 & 0.012 \\
\hline Days of exacerbation days $\cdot \mathrm{yr}^{-1}$ & $17.3 \pm 33.6$ & $34.5 \pm 47.5$ & 0.002 \\
\hline Symptom recovery time days & $9.89 \pm 6.94^{\#}$ & $9.54 \pm 6.96^{\circ}$ & 0.748 \\
\hline
\end{tabular}

\section{DISCUSSION}

The present study is the first to assess, using a symptom-based exacerbation definition, the effect of an inhaled anticholinergic therapy on sputum and systemic inflammatory markers and exacerbations over a 12-month period in patients with COPD. There were no significant differences in levels of sputum IL-6 and MPO or systemic inflammatory markers between the groups, but sputum IL-8 concentration was significantly higher in the tiotropium group at the end of the study. A significant reduction of $52 \%$ in exacerbation frequency, together with a reduction in total exacerbation days and the proportion of patients suffering at least one exacerbation, was demonstrated in the tiotropium group compared with placebo.

COPD is associated with progressive airway and systemic inflammation, and exacerbations are associated with increases in levels of corresponding inflammatory markers [8, 29, 30]. These exacerbations are important events in the natural history of the disease, but the mechanisms by which therapies reduce exacerbation frequency are not clearly understood. It has previously been demonstrated that there are increased levels of sputum IL-6 and IL-8 in COPD patients experiencing frequent exacerbations, suggesting that frequent exacerbators show increased airway inflammation in the stable state [8]. Therefore, it might be postulated that a reduction in airway inflammation might lead to a reduction in exacerbation frequency.

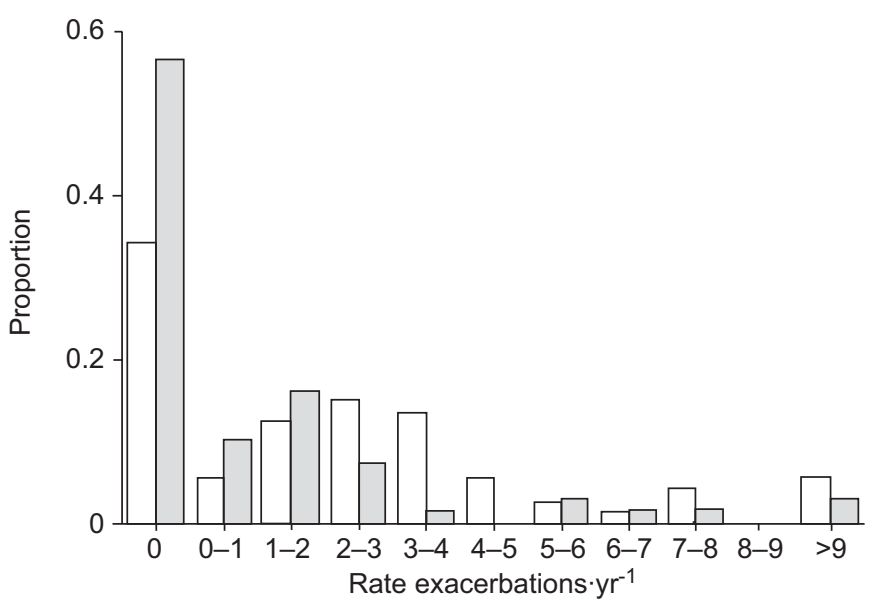

FIGURE 3. Proportion of patients on tiotropium $(\square)$ or placebo $(\square)$ during the study by annual exacerbation rate.
Short-term biopsy studies have demonstrated a reduction in numbers of epithelial mast cells and CD8 cells after therapy with fluticasone and salmeterol/fluticasone $[19,21]$. However, no studies have demonstrated an effect of inhaled therapy on sputum cytokines. It has recently been shown that acetylcholine increases neutrophil chemotactic activity and production of leukotriene $\mathrm{B}_{4}$ in $\mathrm{COPD}$, and this action is attenuated in vitro by tiotropium, thus indicating a potential anti-inflammatory action of tiotropium $[16,17]$. However, in the present study, no effect of tiotropium on sputum IL-6 or MPO level was demonstrated, and thus the reduction in exacerbation frequency cannot be related to changes in airway inflammation.

Surprisingly, tiotropium therapy was associated with a significant increase in the concentration of sputum IL-8. Tiotropium could potentially inhibit cholinergic stimulation of mucus-secreting airway goblet cells, thus causing a reduction in airway mucus and increasing the concentration of cytokines. This is supported by the subjective reporting of reduced sputum production by patients in the present study. In common with previous studies of COPD therapies, no reduction in levels of sputum inflammatory markers was demonstrated, and it is possible that measurement of sputum cytokines is not the optimal means of assessing airway inflammation.

\begin{tabular}{lcc} 
TABLE 4 & $\begin{array}{l}\text { Adverse events occurring in } \\
\text { during the treatment period }\end{array}$ \\
& Tiotropium & Placebo \\
\hline Subjects & 69 & 73 \\
Hypertension & $5(7.2)$ & $1(1.4)$ \\
Myocardial infarction & $3(4.3)$ & $1(1.4)$ \\
Urinary tract infection & $3(4.3)$ & $1(1.4)$ \\
Pharyngitis & $3(4.3)$ & $1(1.4)$ \\
Pneumonia & $2(2.9)$ & $3(4.1)$ \\
Ear infection & $1(1.4)$ & $3(4.1)$ \\
Tooth extraction & $0(0.0)$ & $3(4.1)$ \\
\hline
\end{tabular}

Data are presented as $n$ or $n(\%)$. The treatment period was defined as the period between the start of treatment and end of treatment plus 30 days following the end of treatment. ${ }^{*}$ : excluding exacerbation of chronic obstructive pulmonary disease 
It is well known that systemic inflammation is a factor in COPD. Inhaled fluticasone has been shown to reduce levels of serum CRP, thus indicating a reduction in systemic inflammation [31]. Serum CRP and IL-6 levels were studied in order to assess systemic inflammation, but no differences were found between tiotropium and placebo.

The present trial demonstrated a significant reduction in exacerbation frequency in the tiotropium group, in keeping with previous studies, although a larger (52\%) reduction in exacerbation frequency was found than previously reported. This is the first intervention trial to employ the previously validated method of a daily diary card over $1 \mathrm{yr}$ for the detection of exacerbations $[1,5]$. There has been much debate as to what constitutes a COPD exacerbation, and several definitions have been proposed [5, 32,33]. Some have included an increase in respiratory symptoms from baseline requiring a change in usual therapy. This relies on the patient seeking healthcare assistance, and, as such, presents some associated difficulties. Factors other than the severity of symptoms may prevent the patient from seeking input from a healthcare practitioner. It has previously been shown that $50 \%$ of exacerbations go unreported and that these unreported events also impact on quality of life and are associated with disease progression $[1,5,7]$. The advantage of the diary cards is that all exacerbations, whether reported or unreported, can be detected. Compliance in using the diary card was extremely good in the present trial, indicating their utility as a tool for detecting exacerbations.

Patients in the tiotropium arm demonstrated an improvement in FEV1 and FVC over the year of the study, whereas patients on placebo demonstrated a decline in lung function. Tiotropium has been shown to improve inspiratory capacity, thus reducing dyspnoea, which is an important symptom of a COPD exacerbation [12, 13]. It is this reduction in dyspnoea that is probably a major factor in the reduction in exacerbation frequency demonstrated in the tiotropium group.

Mucus secretion is frequently increased in patients with COPD. This mucus hypersecretion might be associated with airway obstruction and disruption of the mucociliary escalator, and provide an attractive milieu for airway bacterial colonisation. These changes might be expected to be associated with increased inflammation and exacerbation frequency. Secretion from mucous glands is mediated by cholinergic pathways and potentially inhibited by anticholinergics. TAMAOKI et al. [34] showed a reduction in sputum volume using the anticholinergic agent oxitropium. Therefore, a reduction in mucus hypersecretion is a further potential mechanism by which tiotropium might reduce exacerbation frequency. Although quantitative measurements of sputum were not performed in the present study, patients on tiotropium reported a subjective reduction in sputum volume, suggesting that tiotropium might indeed have an effect on mucus secretion.

Patients with COPD may demonstrate lower airway bacterial colonisation, which is associated with increased airway inflammation, disease progression and increased exacerbation frequency $[27,35]$. Therefore, rates of lower airway bacterial colonisation were studied in the present trial, but no differences were found between the tiotropium and placebo arms of the study.
The principal limitation of the present study was difficulty in the use of sputum inflammatory markers, since sputum samples were difficult to obtain, although there was no significant difference between the groups. In addition, there was marked variability in levels of sputum cytokines in the trial, thus reducing the power of the study to detect a significant difference. This may also explain the failure of previous studies to demonstrate an effect of COPD therapies on airway inflammatory markers. Many patients in the present study were taking inhaled steroids, and it might be argued that this was a potentially confounding factor; however, no significant differences in inflammatory markers were demonstrated between those taking and those not taking inhaled steroids.

This was a cohort of patients with moderate-to-severe disease and, as it has been shown that steroid withdrawal results in a deterioration in lung function and increase in exacerbation frequency [36], it was decided that the patients should remain on inhaled corticosteroids.

In summary, the present study was the first year-long trial using the present symptom-based exacerbation definition and daily diary card monitoring. The results of the study showed a significant reduction in exacerbation frequency in chronic obstructive pulmonary disease patients treated with tiotropium, compared with those receiving placebo. However, this effect does not seem to be related to a reduction in airway or systemic inflammation and is likely to be related to reductions in dynamic hyperinflation or airway mucus production. Further studies are now required in order to evaluate the mechanisms of this effect of inhaled tiotropium on exacerbation frequency in chronic obstructive pulmonary disease.

\section{ACKNOWLEDGEMENTS}

The authors would like to thank C. Dawson (Academic Respiratory Medicine, St Bartholomew's Hospital, London, UK) for help with recruitment and data collection and A. Whiley (Dept of Microbiology, St Bartholomew's Hospital, London, UK) for processing microbiological samples.

\section{REFERENCES}

1 Seemungal TA, Donaldson GC, Bhowmik A, Jeffries DJ, Wedzicha JA. Time course and recovery of exacerbations in patients with chronic obstructive pulmonary disease. Am J Respir Crit Care Med 2000; 161: 1608-1613.

2 Hurst JR, Perera WR, Wilkinson TM, Donaldson GC, Wedzicha JA. Systemic and upper and lower airway inflammation at exacerbation of chronic obstructive pulmonary disease. Am J Respir Crit Care Med 2006; 173: 71-78.

3 Soler-Cataluna JJ, Martinez-Garcia MA, Roman Sanchez P, Salcedo E, Navarro M, Ochando R. Severe acute exacerbations and mortality in patients with chronic obstructive pulmonary disease. Thorax 2005; 60: 925-931.

4 Strassels SA, Smith DH, Sullivan SD, Mahajan PS. The costs of treating COPD in the United States. Chest 2001; 119: 344-352.

5 Seemungal TA, Donaldson GC, Paul EA, Bestall JC, Jeffries DJ, Wedzicha JA. Effect of exacerbation on quality of life in patients with chronic obstructive pulmonary disease. Am J Respir Crit Care Med 1998; 157: 1418-1422. 
6 Donaldson GC, Wilkinson TMA, Hurst JR, Wedzicha JA. Exacerbations and time spent outdoors in chronic obstructive pulmonary disease. Am J Respir Crit Care Med 2005; 171: 446-452.

7 Donaldson GC, Seemungal TAR, Bhowmik A, Wedzicha JA. Relationship between exacerbation frequency and lung function decline in chronic obstructive pulmonary disease. Thorax 2002; 57: 847-852.

8 Bhowmik A, Seemungal TAR, Sapsford RJ, Wedzicha JA. Relation of sputum inflammatory markers to symptoms and lung function changes in COPD. Thorax 2000; 55: 114-120.

9 Casaburi R, Mahler DA, Jones PW, et al. A long-term evaluation of once-daily inhaled tiotropium in chronic obstructive pulmonary disease. Eur Respir J 2002; 19: 217-224.

10 Vincken W, van Noord JA, Greefhorst APM, et al. Improved health outcomes in patients with COPD during 1 yr's treatment with tiotropium. Eur Respir J 2002; 19: 209-216.

11 Brusasco V, Hodder R, Miravitlles M, Lee A, Towse LJ, Kesten S. Health outcomes in a 6 month placebo-controlled trial of once-daily tiotropium compared with twice daily salmeterol in patients with COPD. Thorax 2003; 58: 399-404.

12 O'Donnell DE, Flüge T, Gerken F, et al. Effects of tiotropium on lung hyperinflation, dyspnoea and exercise tolerance in COPD. Eur Respir J 2004; 23: 832-840.

13 Celli B, ZuWallack R, Wang S, Kesten S. Improvement in resting inspiratory capacity and hyperinflation with tiotropium in COPD patients with increased static lung volumes. Chest 2003; 124: 1743-1748.

14 Niewohner DE, Rice K, Cote C, et al. Prevention of exacerbations of chronic obstructive pulmonary disease with tiotropium, a once-daily inhaled anticholinergic bronchodilator: a randomized trial. Ann Intern Med 2005; 143: 317-326.

15 Dusser D, Bravo ML, Iacono P, on behalf of the MISTRAL study group, The effect of tiotropium on exacerbations and airflow in patients with COPD. Eur Respir J 2006; 27: 547-555.

16 Profita M, Di Giorgi R, Sala A, et al. Muscarinic receptors, leukotriene $\mathrm{B}_{4}$ production and neutrophilic inflammation in COPD patients. Allergy 2005; 60: 1361-1369.

17 Buhling F, Lieder N, Reisenauer A, Welte T. Antiinflammatory function of tiotropium mediated by suppression of acetylcholine-induced release of chemotactic activity. Eur Respir J 2004; 24: Suppl. 48, 318s.

18 Culpitt SV, Maziak W, Loukidis S, Nightingale JA, Matthews JL, Barnes PJ. Effect of high dose inhaled steroid on cells, cytokines, and proteases in induced sputum in chronic obstructive pulmonary disease. Am J Respir Crit Care Med 1999; 160: 1635-1639.

19 Hattotuwa KL, Gizycki MJ, Ansari TW, Jeffery PK, Barnes NC. The effects of inhaled fluticasone on airway inflammation in chronic obstructive pulmonary disease. Am J Respir Crit Care Med 2002; 165: 1592-1596.

20 Gamble E, Grootendorst DC, Brightling CE, et al. Antiinflammatory effects of the phosphodiesterase- 4 inhibitor cilomilast (Ariflo) in chronic obstructive pulmonary disease. Am J Respir Crit Care Med 2003; 168: 976-982.

21 Barnes NC, Qui Y-S, Pavord ID, et al. Antiinflammatory effects of salmeterol/fluticasone proprionate in chronic obstructive lung disease. Am J Respir Crit Care Med 2006; 173: 736-743.

22 Powrie DJ, Wilkinson TM, Donaldson GC, et al. The effect of tiotropium on diary-based exacerbation frequency in COPD. Am J Respir Crit Care Med 2006; 3: A604.

23 Powrie DJ, Wilkinson TM, Donaldson GC, Wedzicha JA. Tiotropium reduces subjectively reported sputum production in COPD. Eur Respir J 2006; 28: Suppl. 50, 661s.

24 ClinicalTrials.gov. Effect of tiotropium on inflammation and exacerbations in COPD. http://clinicaltrials.gov/ct/show/ NCT00405236?order=1 Date last updated: November 2006. Date last accessed: February 2007.

25 Bhowmik A, Seemungal TAR, Sapsford RJ, Wedzicha JA. Comparison of spontaneous and induced sputum for investigation of airway inflammation in chronic obstructive pulmonary disease. Thorax 1998; 53: 953-956.

26 Barrow GI, Feltham RK. Cowan and Steel's Manual for the Identification of Medical Bacteria. 3rd Edn. Cambridge, Cambridge University Press, 1993.

27 Patel IS, Seemungal TAR, Wilks M, Lloyd-Owen SJ, Donaldson GC, Wedzicha JA. Relationship between bacterial colonisation and the frequency, character, and severity of COPD exacerbations. Thorax 2002; 57: 759-764.

28 Matthews JN, Altman DG, Campbell MJ, Royston P. Analysis of serial measurements in medical research. BMJ 1990; 300: 230-235.

29 Di Stefano A, Capelli A, Lusuardi M, et al. Severity of airflow limitation is associated with severity of airway inflammation in smokers. Am J Respir Crit Care Med 1998; 158: 1277-1285.

30 Wedzicha JA, Seemungal TA, MacCallum PK, Paul EA, Donaldson GC, Bhowmik A. Acute exacerbations of chronic obstructive pulmonary disease are accompanied by elevations of plasma fibrinogen and serum IL-6 levels. Thromb Haemost 2000; 84: 210-215.

31 Sin DD, Lacy P, York E, Man SFP. Effects of fluticasone on systemic markers of inflammation in chronic obstructive pulmonary disease. Am J Respir Crit Care Med 2004; 170: 760-765.

32 Anthonisen NR, Manfreda J, Warren CPW, Hershfield E, Harding G, Nelson N. Antibiotic therapy in exacerbations of chronic obstructive pulmonary disease. Ann Intern Med 1987; 106: 196-204.

33 Rodriguez-Roisin R. Towards a consensus definition for COPD exacerbations. Chest 2000; 117: Suppl. 2, 398S-401S.

34 Tamaoki J, Chiyotani A, Tagaya E, Sakai N, Konno K. Effect of long term treatment with oxitropium bromide on airway secretion in chronic bronchitis and diffuse panbronchiolitis. Thorax 1994; 49: 545-548.

35 Wilkinson TMA, Patel IS, Wilks M, Donaldson GC, Wedzicha JA. Airway bacterial load and FEV1 decline in patients with chronic obstructive pulmonary disease. Am J Respir Crit Care Med 2003; 167: 1090-1095.

36 van der Valk P, Monninkhof E, van der Palen J, Zielhuis G, van Herwaarden C. Effect of discontinuation of inhaled corticosteroids in patients with chronic obstructive pulmonary disease: the COPE study. Am J Respir Crit Care Med 2002; 166: 1358-1363. 